This article was downloaded by: [Australian National University Library]

On: 9 September 2010

Access details: Access Details: [subscription number 907447645]

Publisher Routledge

Informa Ltd Registered in England and Wales Registered Number: 1072954 Registered office: Mortimer House, 3741 Mortimer Street, London W1T 3JH, UK

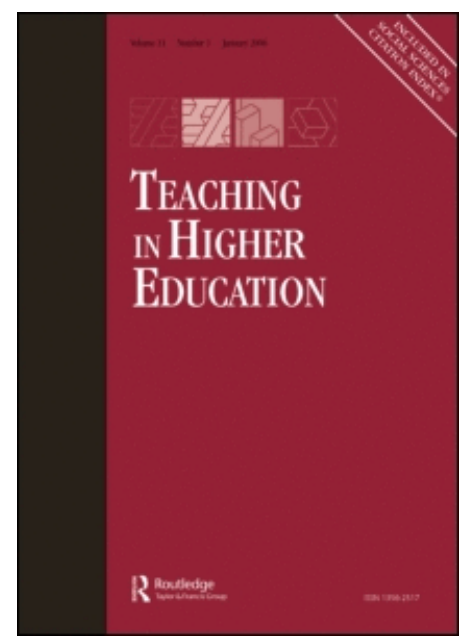

\title{
Teaching in Higher Education
}

Publication details, including instructions for authors and subscription information:

http://www.informaworld.com/smpp/title content=t713447786

\section{Extended metaphors for pedagogy: using sameness and difference}

Susan Carter ${ }^{\mathrm{a}}$; Rod Pitcher ${ }^{\mathrm{b}}$

${ }^{\text {a }}$ Centre for Academic Development, University of Auckland, Auckland, New Zealand ${ }^{\mathrm{b}}$ Centre for Educational Development and Academic Methods, Australian National University, Canberra, ACT, Australia

Online publication date: 09 September 2010

To cite this Article Carter, Susan and Pitcher, Rod(2010) 'Extended metaphors for pedagogy: using sameness and difference', Teaching in Higher Education, 15: 5, 579 - 589

To link to this Article: DOI: 10.1080/13562517.2010.491904

URL: http://dx.doi.org/10.1080/13562517.2010.491904

\section{PLEASE SCROLL DOWN FOR ARTICLE}

Full terms and conditions of use: http://www.informaworld.com/terms-and-conditions-of-access.pdf

This article may be used for research, teaching and private study purposes. Any substantial or systematic reproduction, re-distribution, re-selling, loan or sub-licensing, systematic supply or distribution in any form to anyone is expressly forbidden.

The publisher does not give any warranty express or implied or make any representation that the contents will be complete or accurate or up to date. The accuracy of any instructions, formulae and drug doses should be independently verified with primary sources. The publisher shall not be liable for any loss, actions, claims, proceedings, demand or costs or damages whatsoever or howsoever caused arising directly or indirectly in connection with or arising out of the use of this material. 


\title{
Extended metaphors for pedagogy: using sameness and difference
}

\author{
Susan Carter $^{\mathrm{a} *}$ and Rod Pitcher ${ }^{\mathrm{b}}$ \\ ${ }^{\mathrm{a}}$ Centre for Academic Development, University of Auckland, Auckland, New Zealand; ${ }^{\mathrm{b}}$ Centre \\ for Educational Development and Academic Methods, Australian National University, Linnaeus \\ Cottage, Canberra, ACT, Australia
}

(Received 16 June 2009; final version received 29 March 2010)

This article looks at the use of extended metaphor in teaching. Our case studies as two teachers using metaphor in different settings show how metaphor is experienced by learners to different pedagogical effect. The article demonstrates that metaphor can be used not only for the similarity between vehicle and target systems, but also for the difference. In the subject of electronics, extended metaphor (water, waves and webs) scaffolds learning by merit of the similarity of the vehicle system to the target. However, when teaching doctoral students to improve their writing skills, extended metaphor exploits the difference between vehicle and target. In this case the frustration of academic challenge is defused by using metaphors that are homely and ordinary in contrast to the formal academic genre of thesis writing. Our experience in using metaphors to teach provides support for the theory that they may be monistic (forgotten once they have fulfilled the pedagogical scaffolding task) or dualistic (remembered because both systems remain in play). The article prompts other higher education teachers to more consciously consider the potential of metaphor as a pedagogical aid.

Keywords: metaphor; pedagogy; teaching electronics; doctoral support; teaching writing

\section{Introduction}

Dictionaries convey simple meaning by definition; metaphors by definition convey complex meaning. Education not only entails definition, but it also often requires the conveyance of complex meaning. Metaphors do this well, and thus frequent the language of teaching and learning. Many people from Aristotle to modern day thinkers have observed that a new area of knowledge can only be learnt by building it onto a basis formed of knowledge in another area (Ricouer 1994 gives a good analyses of Aristotle on metaphor, 9-43). Old knowledge can be a metaphorical vehicle, which conveys new target knowledge. Schön (1963) demonstrates that thinking of paintbrush bristles as forming channels down which the paint flowed (a metaphorical vehicle, since there are not literally channels) enabled the design of a smoother flowing paintbrush (73-6). His examples, like ours, are extended metaphors; like Schön, we discuss the effect of our use of metaphor. Schön calls metaphor the 'displacement of theory' because this is the effect of extending a metaphor; the connotations and theory of the known concepts inform the unknown. We use the simpler term 'metaphor', but endorse Schön's emphasis on

*Corresponding author. Email: s.carter@auckland.ac.nz 
the extent of what is transferred when metaphors are used. Adding to the current literature, our case studies as teachers using metaphors in two very different situations (technology and generic doctoral support) illustrate their usage as teaching tools. The difference in our teaching use of metaphors demonstrates their multiple facets.

Metaphors transfer meaning at many levels (see Cazeaux 2007 for a history of metaphor theory). Metaphors are suspected as tricksters, sly in their transference. As de Man (1979) puts it, 'tropes [figures of speech which include metaphors] are not just travellers, they tend to be smugglers, and probably smugglers of stolen goods' (17). Below Pitcher cautions about the misconception that might be smuggled in with electronic's metaphorical vehicles: waves, water and webs. More positively, as Pitcher also shows with his own teaching metaphors, the transfer of baggage across borders means that 'metaphor is one of the central ways of leaping the epistemological gap between old knowledge and radically new knowledge' (Petrie 1993, 440). The linguistic black-market work is profitable; as Ricouer hypothesises, "the "metaphoric" that transgresses the categorical order also begets it' $(1994,24)$. Destabilising the innocence of the literal word, metaphors allow conceptualisation to be more fluid.

Learning is advanced through metaphor's cognitive challenges: 'just as the repeated use of a hammer may strengthen the arm, so the repeated use of metaphors may strengthen the powers of analysis and synthesis' (Sticht 1993, 485). Schön (1963) both demonstrates the efficacy of metaphors as problem solvers, and celebrates their power: 'The metaphor is apt to seem peculiarly satisfying, intriguing, beautiful, or simply to have a kind of "pull" to it. There is often a feeling of increased vitality" (67). Classroom metaphors prompt student engagement. Metaphor's efficacy can enable conceptual threshold breakthroughs, transformative learning described for example by Wisker and Robinson (2009).

It is of course not new to link education and metaphor: 'Metaphor makes things exciting and understandable and, as such, has been applied to education' (Low 2008, 212). The metaphors that we discuss confirm that metaphors 'invite educators to explore comparisons, make them notice similarities, and use a situation as an image of another' (Saban 2006, 300). Furthermore, metaphor can be consciously used to prompt active learning; Charteris-Black (2004) notes that 'the act of stretching the resources of language involved in metaphor is a way of forging a stronger interpersonal bond between speaker and hearer' (12). Because Carter's metaphors assume a shared everyday experience, they rely on the interpersonal bond between her and her students. Metaphors are often the best way to articulate abstract truths (Lakoff and Johnson 2003; Reynolds 2001). Regularly they provide the language of new technological systems. Indeed, 'all language, including scientific language, is tropological' (Ortony 1993, 3). They support the research process, where, for example, the comparison of the thesis process to a long and arduous journey may make the steeper passages more endurable (Bartlett and Mercer 2001). Extended metaphors can facilitate the structure of a piece of writing. The link between education and metaphors is well acknowledged.

\section{The mechanics of metaphors}

Metaphors, then, can provide new terms where none have previously existed. This, according to Martin and Harre, is why the metaphor is so important in the explication of new scientific theories, as well as providing insights and explanations, 
it can provide new terminology for a newly developed field $(1982,101)$. The new terms have a more important role to play than expressing the current state-of-play. They and the images they portray can form the basis for new theoretical insights, as Schön (1963) notes. These 'theory-constitutive metaphors' are then the basis for further progress and theory development in the field (Boyd 1993, 371). Kittay (1989) identifies the models used in science as 'extended metaphors' noting that 'it is within a carefully conceived "chaos" that metaphors attain an irreducible cognitive content and their special meaning' (327).

Scaffolding metaphors enable the learning of new knowledge, but they have certain inherent limitations. One limitation is that the metaphor is neither simply the vehicle nor the target. This problem of slippage between the two can be overcome to some extent by using multiple metaphors together. In this way the metaphorical view of the new territory is expanded by the superimposition of various new images so that the understanding developed becomes more comprehensive (Yob 2003, 134). Thus, an alternative metaphor may open up a complementary theoretical perspective on the subject (Saban 2006, 312). Low (2008) also suggests that more than one metaphor should be used to compensate for, and bring forward, the parts of the explanation that are backgrounded by another metaphor (216). However, Pitcher's practical experience in teaching electronics suggests that sometimes using more than one metaphor makes for confusion, and that using one simple metaphor enables the student to learn more quickly.

When metaphors are used in science they are part of a way of thinking; they function as structure maps between two different, complex systems. Thus it is not the nouns of the metaphor (e.g. 'water') but the inherent verbs (e.g. 'flows') that convey the most significant meaning. Gentner (1982) notes that it is the relationships of the vehicle domain, which are carried over into the target domain (109). Gentner also discusses the factors which contribute to a good scientific analogy. If the metaphor is to be a system of structural mapping between the relationships in the vehicle and target domains, then it is important to foreground the relationships that are crucial to the analogy (Gentner 1982, 113). The vehicle domain should be familiar (Gentner 1982, 113). Thus another limitation is that metaphors rely on a sound understanding of the vehicle concept; if English is not the student's first language they may lack some of the connotations of the vehicle term. However, familiarity itself is insufficient; there must be understanding of the relationships, rules and actions as well for the metaphor to work for the learner.

Learners do not have the same perspective as the teacher who uses the metaphor. Wilbers and Duit (2006) point out that the metaphor, or analogy in their terms, works differently for the teacher who already knows than for the student who is building a new mental construct: 'To put it in a nutshell: a student's heuristic is built on mental images rather than propositionally based knowledge (as opposed to the teacher's post-festum analogy)' (37). In other words, careful description of something you know well (post-festum knowledge) may not be adequate for someone without your knowledge who receives your description as a proposition. Most of us have failed as travellers to find the propositional turning we were assured by the postfestum knower that we couldn't miss. A vehicle chosen without regard for the students may actually impede understanding.

A second important consideration is the clarity of the metaphor in suggesting the degree of mapping between the domains. For instance, as Gentner (1982) points out, 
mapping either one relationship in the base domain onto two or more in the target domain, or mapping two or more in the base domain onto one in the target domain will cause confusion (114). Ortony confirms the slipperiness of metaphors, pointing out that we can talk about things using 'metaphors that are essentially misleading and inaccurate' $(1993,6)$. Teachers need to be alert to the limitations of the metaphors they use. We demonstrate the action and limitation with metaphors widely used in electronics, often using water as a parallel: electricity 'flows' and signals radiate in 'waves'. At the same time in electronics, 'webs' describe radiating networks of interconnections.

The next section proposes metaphors are forgotten or remembered because they work in different ways in our teaching of electronics (Pitcher) and writing skills (Carter). Specific metaphors - water, waves and webs - dominate the text books of electrical theory. The electrical theory example shows how the known, the vehicle of the metaphor, can convey the not known, the target. A data gathering exercise shows that students who learned electronics via these metaphors forgot the metaphors that scaffolded their comprehension once they had grasped the target concepts. Thus these metaphors are monistic ones because 'there is a complete deletion of the literal sense of the metaphor' (Mooij, 1976, cited in Nöth 1990, 129-30). The vehicle is not present in the speaker and listener's imaginations; water is not literally envisioned. To use Schön's (1963) helpful term, it is the theory about water that is displaced rather than the image of water itself.

Metaphors are also helpful in teaching writing skills to those adults who fail to simply see what works well. Here what is being learned is not fresh unknown knowledge, but how to perform better at a familiar communication task. The covert rules of a semiotic system - academic writing - need to be exposed so that they can be understood and applied. Williams (1990) captures a recognisably sharp tone of frustration with writing when he observes that practice is harder than principle: "Telling me to "Be clear" is like telling me to "Hit the ball squarely". I know that. What I don't know is how to do it' (1). Examples of stock in trade metaphors used when teaching writing to doctoral students show another different function of pedagogical metaphors; their ability to lighten tense moments by shifting from the academic register to the informality of lived experience. The ordinariness of the quotidian vehicle brings with it familiarity and thus confidence. When writing is described as taking the reader for a trip through your ideas, the images of car and trip are an efficacious metaphorical vehicle. These are dualistic metaphors because the literal remains in play (Mooij, 1976, cited in Nöth 1990, 129-30). Our two case studies show the different potential of monistic and dualistic metaphor use.

\section{Water, waves and webs: electronic's scaffolding metaphors}

Water as the metaphorical vehicle for electricity - electricity is compared to water in a pipe - is used by almost all teachers of electrical theory, and appears in almost every text book, often with pictures (for example, see Phillips 1993). Waves and webs are less ubiquitous metaphors, but widely used.

Students learning basic electrical theory are encouraged to make an analogy with water. The amount of water flowing through a pipe is presented as a comparison with current flowing through a wire. Water flows at a rate depending on the pressure applied by a pump of some sort, just as electricity flows at a rate depending on the 
electro-motive force provided by a battery or generator. Special devices such as flow and pressure meters can measure these quantities.

The metaphor can be carried further. If a pipe breaks then the water no longer reaches the point where it is to be used; a broken wire will stop electricity from reaching the appliance plugged into the socket. So, in both cases, a complete circuit is required. Taps are similar to electric switches in turning the flow on and off. When water meets a division in the pipes, the flow divides up in a proportion which depends on the nature of the pipes. More water flows down a bigger diameter pipe than a small one, since there is less restriction and resistance. Similarly, electric current flow divides at a wiring junction, and the amount of current in each branch is inversely proportional to the resistance in that branch. Thicker wires can carry higher currents because their resistance is lower. The vehicle of running water thus provides a step from what may be taken as common knowledge for most people to the new concepts associated with electricity.

Whilst the metaphor works to this extent, if taken further the correspondence begins to break down. Water can be seen flowing in a pipe made of a transparent material, but electrons cannot be seen flowing in a wire, being detected only by their effects. If a pipe breaks or is cut, water flows out of the end; but electricity does not flow from the end of a broken wire, it simply stops. Harrison and Treagust (2006) describe this limitation, and give another example of a train with passengers used to describe an electronic circuit but abandoned because of its limitations. Perhaps the biggest difference, and potentially the most dangerous, is that, whereas water is fairly innocuous, electricity in high voltages is dangerous and can kill. Students need to be alert to the limitations of the metaphor.

Water also yields the metaphor of waves. Radio signals radiated from an antenna are said to propagate in waves like ripples radiating from a stone dropped into a pool of water. The stone sets up a series of ripples which radiate from the impact point in all directions across the surface of the pool, are reflected by obstacles and the shore line, interacting, cancelling and reinforcing each other, until the energy of the impact has dissipated. The high and low points of the wave in water correspond to the oscillations in the fields which form the radio signal.

The extended metaphor works reasonably well. The ripples produced by other sources such as wind, or stones dropped by someone else, might interfere with the ripples produced by the dropped stone in the above experiment. Similarly, there are other sources of radio waves that can interfere and interact with our wanted radio signals. At this level the metaphor provides a useful analogy with the theory.

The idea of a web is sometimes used to introduce the idea of the way in which different stations - such as radio stations or computers - are connected together for the purpose of communicating with each other. The image portrayed is that of a radiating network of interconnections. Yet this metaphor is limited.

In a spider's web, information on the presence of prey is transmitted only one way; the spider makes every effort not to signal back until the prey is irretrievably trapped. Communications networks, however, invariably move data both ways. A spider's web has no connection to the webs of other spiders; communications networks often have a number of control centres or nodes, which are connected to each other, each with its own group forming a local network. The limitations of these metaphors used to teach electronics need to be considered in their use and probably need to be overtly discussed. 


\section{Electronic's metaphor learning experience: a forgotten one}

Having used these extended metaphors in teaching for some time, and growing increasingly aware of their strengths and their limitations, Pitcher grew interested in learners' experience of electronical metaphors. In unstructured, informal interviews, he asked 12 electrical engineers how they felt about electronical metaphors and whether or not they saw them as useful. Since they already knew electronics, they were asked whether the 'water-in-the-pipe' metaphor had been used in explaining the theory to them, and if so, whether it helped them understand the electrical theory. They were also asked whether or not they experienced any problems relating the theory to the metaphor. In addition, Pitcher asked four teachers of electronics whether they found the metaphor useful as a teaching aid or found any problems.

As well as the interview data, Pitcher drew on his own experience learning electronics and teaching it to others over a number of years. Because he first learnt basic electrical theory in high school physics and the text book for that course (Smith and Smith 1961) uses metaphors, he accepts that he did, in fact, initially encounter the metaphors used in electrical theory. At first he was concerned that he had forgotten his early encounter with the metaphors, until he found that he was not alone in doing so, and that, in fact, few people explicitly remember electronic theory metaphors.

To limit the data collected to a usable amount, the interviews were restricted to the topic of the water-in-a-pipe metaphor rather than covering all the metaphors used in teaching electrical theory. That metaphor is so ubiquitous that it is unlikely that anyone could be found in electronics or radio who has not heard of it. Yet strikingly, no one seemed to remember definitely whether or not the water-in-a-pipe metaphor had influenced their learning. Indeed, most could not even remember that it had been used in teaching them the theory.

The monistic nature of this metaphor (where the vehicle concept is largely absent) is demonstrated by the fact that the participants forgot about the use of the water-ina-pipe metaphor. Participants seemed to forget the metaphor as soon as its usefulness was over. For instance, if the water-in-a-pipe metaphor is used to illustrate current flow in a wire, then as soon as the teacher develops the theory further the metaphor is put aside. This would help to explain the fact that few people seem to find the inconsistencies in the metaphoric illustration confusing; the inconsistencies occur in areas outside of where the teacher situates the metaphor.

In depth interviews with four teachers of electronics theory showed that they knew whether or not they used the metaphor, and whether they found it useful. The teachers were conscious of their pedagogical use of metaphor. Metaphors were used when the learners had very little knowledge of the topic, and were not used when they had some basic knowledge. One person, who used the metaphor at some times but not at others, was able to describe the way he decided whether or not to use it.

This teacher decided on the basis of the students' responses to the theory delivered without using metaphors. Only if the students did not comprehend the theory without the use of metaphors did he explain again using metaphors. If they comprehended the theory without the metaphorical references then he moved on without using metaphor.

The above example of the teacher whose use of the metaphor is dependent on the response of his students is similar to Pitcher's own experience. Both use the approach 
of telling the students about electrons and electricity, firstly without the metaphor. If anyone did not understand, then the metaphor was used. Those students who do not understand at first were usually helped by the metaphor and almost invariably understand the electronics theory after the metaphor is used.

If teachers were sure about their use of metaphors, why are these metaphors so unmemorable for students? Black makes a comparison between 'a successful metaphor [that] is realised in discourse' $(1993,3)$, altering perception forever, and the view from an aeroplane. The view theoretically existed before aeroplanes were invented and enabled the view to be seen. Only when a 'view' is seen does it come into existence; similarly, only when a metaphor makes its comparison through cooperative communication does that perspective of the thing being metaphorically discussed exist. Black (1993) describes metaphors as "cognitive instruments," indispensable for perceiving connections that, once perceived, are then truly present' and as such they are like a view that was previously unseen (such as the view from the plane, or a view in slow motion enabled by film) but once seen, are accepted as factual (37). If one believes that any view of the world is always seen from a particular perspective, the metaphor can create such a perspective (38). Black's proposal captures the solidness of metaphors once they are established, and we suspect that their invisibility as metaphors occurs because the metaphor is so successful that it vanishes as a medium in accordance with Mooij's (1976) monistic model (cited in Nöth 1990, 129-30).

Another possible explanation for the fading of the memory might be that it protects the student from the effects of any inconsistencies in the metaphor between the vehicle and target domains. When the student proceeds to more advanced concepts such inconsistencies are more likely to cause confusion. Thus there would be an advantage in forgetting the metaphor.

\section{Guests, birth, travel and messy house: memorable metaphors for the writing process}

Extended metaphor to clarify writing technique seems to register in student consciousness, however. Carter's metaphors are dualistic in Mooij's (1976) model, but also efficaciously defuse the frustration with academic writing difficulty. In her position providing generic support to doctoral candidates Carter uses several metaphors that seem to help candidates to conceive of their larger process.

Providing functional metaphors is, Carter suspects, how evangelists, counsellors and advisors (and higher educationalists) work effectively to make the world a better place in quite real terms (see too Berman and Brown, 2000, for their recognition of metaphors' power). The right metaphor can rescue someone foundering amongst dysfunctional metaphors, or so despondent that their metaphors have run dry. Brause (2000) observes shrewdly in her advice to doctoral candidates: 'if you flourish in circumstances where you feel victimized and totally dependent on others, then consciously choose the metaphors which reflect this behaviour (e.g. hurdles, maze and game). Conversely, if you pride yourself on your ability to turn any situation into one which is enjoyable and beneficial to you, then use metaphors that reflect that stance (e.g. journey and gardening)' (16). Higher education teachers whose work supports research projects are likely to recognise the value of metaphors for support. A stock of sturdy metaphors is like a collection of nicely sharpened pencils. Here are Carter's. 
The visiting guest tour can explain signposting in thesis writing. This one is especially relevant to international students. Imagine that you have a friend arriving in your city and you will spend one day showing them the sights in your car. You could just say 'Get in the car' but they will be happier if you say 'Get in the car. I am taking you up Mt Eden, to the museum, and to the West Coast'. They will be even happier if you tell them about the 360 degree view from the mountain, about the section in the museum that is unique and interesting and about the distinctive features of the West Coast. Even better, mention the best coffee in town that will be en route as the journey sets out, and the place for lunch near the museum that has wonderful food at reasonable prices and the sunsets to be enjoyed overlooking the last beach on the stop. And even so, in your thesis introduction you might persuasively explain not just where you are going, but why, and even more persuasively, what is in it for the reader.

Another metaphor, the guest-in-the-home describes the need for tidiness and correct signalling of direction. Just as we tidy up when guests are due, removing the shoes, bags and coats from just inside the door and the layers of correspondence from the dining table, so we want our writing to be free of the clutter that has sustained its development. Some of what must be taken away may be about the guest's arrival, yet it should not be lying round when they arrive. Clean, clear and comfortable with personal touches that add style is the ideal. The examiner is the awe-inspiring visitor to thesis prose.

To extend the metaphor further, when we signal that we are heading in one direction, we should not leave small tables or chairs (let alone scattered debris) in the way of access. We should not head into the broom cupboard when we say 'Come through to the dining room'. With writing, too, when a subtitle opens a new topic, the promised topic should immediately follow.

Packaging is another metaphor to describe that turning point with a thesis when the writer must shift their head from a writer's perspective to the reader's. At this point they have the goods, and their job is a seller's one of packaging the data into a form most desirable to the customer, the reader in this case. They should no longer be concerned with the sequence of events in which they discovered their material, but rather, with the sequence of textual representation that will make the material accessible and interesting.

For some learners the stitch-tension metaphor can be applied to writing. Just as textile tension should be evenly maintained over the whole garment when sewing, knitting or weaving to avoid something loose, floppy and stretchy in one place, tight and impenetrable in another, so with writing the tension is often (although not always) best kept even. A short historic overview should not change density according to a surfeit of interesting material in one area and a dearth of knowledge in another. That this metaphor would only be suitable for those who sew or knit or weave points to the need for metaphor to match the learner. When international students have different frames of reference, pedagogic metaphors must match their personal framework of experience.

There are other metaphors. Writing conventions are like traffic rules. Signalling a right-hand turn with 'however' and then steaming straight through the intersection with what is really 'furthermore' intent will disorient the reader. For the thesis writer who is also a mother, birth comparison contextualises the panic felt in the transition 
that precedes submission. A sense of inadequacy and panic may just be symptomatic of the quite healthy fact that the thesis is almost born.

We speculate that the efficacy of these metaphors in teaching writing is, in contrast to Aristotle's comparison model (in which comparability is the key to metaphor success), based on the difference between the vehicle and the target. Metaphor distances at the same time as it connects. Why might this be useful? Doctoral candidates have an emotional relationship to their work. They are often possessive, protective and defensive, and yet anxiously aware that years of work hangs on their writing's ability to satisfy others. Stepping back from the emotional site of the writing to talk about driving or knitting or entertaining a visitor in a cluttered house removes the author from their protective instincts towards their work, and grounds it in everyday frustrations and conventions that are less emotionally fraught.

Further, metaphoric detachment allows a Brechtian detachment of the principle being explained from the individual writing performance. Brechtian principle comes from a dramatic technique whereby action is dislocated from its usual embodiment, as when a male actor plays the role of a distressed female. The performance of femininity conventions is more startlingly visible than when a woman plays the role. By bringing in a metaphorical vehicle from the everyday world, well-known principles are detached from the emotional site of the thesis writing. The need for logical signalling is a general principle of semiotic systems. Principles of courtesy, mechanical logic and order are quite common in social exchange; an individual who has difficulty recognising his or her own writing problems is likely to recognise these social-exchange and mechanical-logic principles as ones that are achievable.

Finally these extended metaphors provide narrative relief. Quite simply, this is a moment when the teacher metaphorically enacts a small skit, moving to the familiar and non-academic, to what is called 'low genre' in art history terms. This is not quite as upbeat as Shakespeare's clowning interludes but shares some resemblance with, say, Macbeth's porter at the door scene. The high moment of anxiety is defused by something common, discordant because slightly absurd and memorable for its release of tension.

The memory factor with these metaphors that distance, ground, defuse emotionally and provide light relief to a situation of frustration is counter to that with the scaffolding electronics metaphors. In Carter's experience, these metaphors are remembered; several students have reported weeks later that 'it was so helpful to think "now I am packaging," or "now I am tidying," or "that thing with the car trip; that really helped"'. Perhaps these metaphors are remembered not only because they are dualistic, but also because they remove tension. Their task was different from the simple scaffolding of those science metaphors no longer visible once their scaffolding task was completed.

\section{Conclusion}

It matters little whether metaphors are remembered or not, simply that they do their different tasks efficiently. Metaphors may scaffold learning by using the similarity of vehicle and target systems. They can also defuse emotion by reinstating the ordinary world over the pressures of the academic, making use of difference rather than similarity. Our teaching examples confirm Mooij's (1976) distinction between 
monistic and dualistic metaphors, but this seems less important than the fact that discussion gave us a better awareness of the way that our metaphors enable learning in our different teaching areas.

Teachers in higher education reflecting on their own teaching might similarly check the baggage that metaphor smuggles into the classroom. If the metaphors are the forgettable monistic ones that scaffold learning, there may be limitations when similarity breaks down. Learner's familiarity with the vehicle is crucial, an important consideration when English is not the first language. Teachers might also make conscious use of the power of dualistic metaphor to defuse tension around academic formality. The right metaphor in a stressful learning situation can be a conceptual threshold into understanding.

\section{Acknowledgements}

Our thanks and appreciations go to Dr Gerlese Åkerlind of the Centre for Educational Development and Academic Methods at the Australian National University for her thoughtful and constructive comments on an earlier draft of this paper.

\section{References}

Bartlett, A., and G. Mercer. 2001. Mostly metaphors: Theorizing from a practice of supervision. In Transforming (R)elations, ed. A. Bartlett and G. Mercer, 55-69. New York: Peter Lang.

Berman, M., and D. Brown. 2000. The power of metaphor: Story telling and guided tours for teachers, trainers and therapists. Carmarthen, UK: Crown House.

Black, M. 1993. More about metaphor. In Metaphor and thought, ed. A. Ortony, 19-41. Cambridge: Cambridge University Press.

Boyd, R. 1993. Metaphor and theory change: What is "metaphor" a metaphor for? In Metaphor and thought, ed. A. Ortony, 481-532. Cambridge: Cambridge University Press.

Brause, R.S. 2000. Writing your doctoral dissertation: Invisible rules for success. London and New York: Falmer Press.

Cazeaux, C. 2007. Metaphor and continental theory: From Kant to Derrida. London: Routledge.

Charteris-Black, J. 2004. Corpus approaches to critical metaphor analysis. Houndsmills, UK: Palgrave Macmillan.

de Man, P. 1979. The epistemology of metaphor. In On metaphor, ed. S. Sacks, 11-28. Chicago, IL: University of Chicago Press.

Gentner, D. 1982. Are scientific analogies metaphors? In Metaphor: Problems and perspectives, ed. D.S. Miall, 106-32. Sussex: Harvester Press.

Harrison, A.G., and D.F. Treagust. 2006. Teaching and learning with analogies: Friend or foe? In Metaphor and analogy in science education, ed. P.L. Aubusson, 11-24. Dordrecht, The Netherlands: Springer-Verlag.

Kittay, E.F. 1989. Metaphor: Its cognitive force and linguistic structure. Oxford: Clarendon.

Lakoff, G., and M. Johnson. 2003. Metaphors we live by. 2nd ed. Chicago, IL and London: University of Chicago Press.

Low, G. 2008. Metaphor and education. In The Cambridge handbook of metaphor and thought, ed. R.W. Gibbs Jr., 212-31. Cambridge: Cambridge University Press.

Martin, J., and R. Harre. 1982. Metaphor in science. In Metaphor: Problems and perspectives, ed. D.S. Miall, 89-105. Sussex: Harvester Press.

Mooij, J.J.A. 1976. A study of metaphor, on the nature of metaphorical expressions, with special references to their reference. Amsterdam: North-Holland. 
Nöth, W. 1990. Handbook of semiotics. IN: Indiana University Press. http://books.google.co. nz/books?id $=$ rHA4KQcPeNgCandpg $=$ PA129andlpg $=$ PA129anddq $=$ metaphor + substitution + comparisonandsource $=$ blandots $=\mathrm{dcm} 3 \mathrm{y}-\mathrm{rR} 1$ landsig $=\mathrm{p} 7 \mathrm{c}-\mathrm{m} 9 \mathrm{BcV} 7 \mathrm{ciS} 18 \mathrm{pLxH} 2 \mathrm{bTQ} 8 \mathrm{adsandhl}=$ enande $=\mathrm{COsuSr} \_\mathrm{jF} 5 \mathrm{~b} 8 \mathrm{tgPO} 0 \mathrm{Iy} 1 \mathrm{CAandsa}=\mathrm{Xando}=$ book_resultandet $=$ resultandresnum $=$ 2\#PPP1,M1 (accessed June 10, 2009).

Ortony, A., ed. 1993. Metaphor, language and thought. In Metaphor and thought, 1-18. Cambridge: Cambridge University Press.

Petrie, H.G. 1993. Metaphor and learning. In Metaphor and thought, ed. A. Ortony, 438-61. Cambridge: Cambridge University Press.

Phillips, P. 1993. Electrical fundamentals. South Melbourne: Thomas Nelson Australia.

Reynolds, T.A. 2001. Case studies in cognitive metaphor and interdisciplinary studies: Physics, biology, narrative. New York: Columbia University.

Ricouer, P. 1994. The rule of metaphor: Multi-disciplinary studies of the creation of meaning in language. Trans. R. Czerny. London: Routledge.

Saban, A. 2006. Functions of metaphor in teaching and teacher education: A review essay. Teaching Education 17, no. 4: 299-315.

Schön, D.A. 1963. Displacement of concepts. London: Tavistock.

Smith, R.T., and J.E. Smith. 1961. A general school physics. Adelaide: Rigby.

Sticht, T.G. 1993. Educational uses of metaphor. In Metaphor and thought, ed. A. Ortony, 474-85. Cambridge: Cambridge University Press.

Wilbers, J., and R. Duit. 2006. Post-festum and heuristic analogies. In: Metaphor and analogy in science education, ed. P.L. Aubusson, 37-49. Dordrecht, The Netherlands: SpringerVerlag.

Williams, J.M. 1990. Style: Towards clarity and grace. Chicago, IL: University of Chicago Press.

Wisker, G., and G. Robinson. 2009. Encouraging post-graduate students of literature and art to cross conceptual thresholds. Innovations in Education and Teaching International 46, no. 3: 317-30.

Yob, I.M. 2003. Thinking constructively with metaphors. Studies in Philosophy and Education 22: $127-38$. 